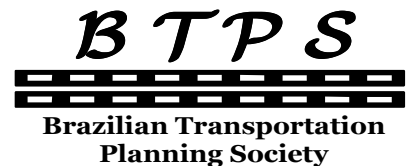

Planning Society
Journal of Transport Literature

Vol. 7, n. 3, pp. 192-213, Jul. 2013

Research Directory
JTL | RELIT

www.transport-literature.org ISSN 2238-1031

\title{
Otimização do rodízio de tripulações do sistema de transporte público
}

[Optimization the crew rostering assignment for public transport systems]

\author{
Victor Teixeira de Melo Mayrink, Gustavo Peixoto Silva*
}

Pós-Graduação em Engenharia Elétrica - COPPE/UFRJ - Brasil, Universidade Federal de Ouro Preto - Brasil

Submitted 21 Jun 2012; received in revised form 30 Oct 2012; accepted 24 Nov 2012

\begin{abstract}
Resumo
Este trabalho aborda o Problema do Rodízio de Tripulações (PRT) do sistema de transporte público. O PRT consiste em atribuir a cada tripulação uma sequência de jornadas para os dias úteis, sábados e domingos de um dado horizonte de planejamento. Um modelo que represente o problema deve considerar tanto restrições operacionais como trabalhistas, tais como: tempo mínimo de repouso, folgas no período, turno de trabalho, entre outras. Neste trabalho o problema foi resolvido em duas etapas. Inicialmente foi resolvida uma sequencia de problemas de designação das jornadas diárias. Nesta sequencia cada modelo de designação, de um dia para o dia seguinte, tem como objetivo tornar a escala tão equilibrada quanto possível, minimizando a quantidade de horas extras e de ociosidade sem se preocupar com as folgas obrigatórias. A partir da solução dos sucessivos problemas de designação é apresentado um segundo modelo de otimização inteira, ainda inédito na literatura, para atribuir as folgas às tripulações. Este modelo garante que cada tripulação tenha suas folgas devidamente atendidas, seja pelo número máximo de dias trabalhados consecutivamente, como também pelo direito de uma folga no domingo a cada sete semanas. 0 objetivo deste modelo é minimizar o número máximo de tripulações do tipo "folguista", garantindo que as restrições das folgas sejam atendidas. Os modelos foram testados com dados de duas empresas que operam no sistema de transporte público, e os resultados foram comparados com as soluções adotadas pelas empresas. Assim foi possível verificar reduções no número de tripulações que variam entre $8 \%$ e 54\%, além de reduções de 13\% no número de horas extras pagas pelas empresas.
\end{abstract}

Palavras-Chave: transporte público, otimização da escala mensal, problema do rodízio de tripulações.

\begin{abstract}
This paper addresses the Crew Rostering Problem (CRP) in a transit bus company. The CRP attempts to obtain a sequence of daily journeys for weekdays, Saturdays and Sundays, for a given planning horizon. Any model that represents the problem should consider both operational and labor constraints, such as minimum rest time at home and appropriate days off. In this work the problem is solved as a sequence of assignment problems for the daily journeys. This model builds a rostering as balanced as possible, minimizing the amount of overtime and crew idleness. Starting with the solution provided by the assignment model, a new model is presented in order to include the days off to the crews. This model assures that each crew has its days off properly assigned, either by the maximum days worked consecutively, or in order to have a Sunday free each seven weeks. The objective function is to minimize the number of crews covering the days off for regular crews. The models were tested with real data from two bus companies, and the results were compared with the solutions adopted by the companies. Thus it was possible to verify reductions in the number of crews ranging between $8 \%$ and $54 \%$, plus reductions of $13 \%$ in the overtime paid by the companies.
\end{abstract}

Key words: public transportation, monthly rostering, crew rostering problem.

*Email: gustavo@iceb.ufop.br.

\section{Recommended Citation}

Mayrink, V. T. M. and Silva, G. P. (2013) Otimização do rodízio de tripulações do sistema de transporte público. Journal of Transport Literature, vol. 7, n. 3, pp. 192-213.

- JTL/RELIT is a fully electronic, peer-reviewed, open access, international journal focused on emerging transport markets and published by BPTS - Brazilian Transport Planning Society. Website www.transport-literature.org. ISSN 2238-1031.

This paper is downloadable at www.transport-literature.org/open-access. 


\section{Introdução}

Resolver o Problema de Rodízio de Tripulações (PRT) consiste em gerar, para cada tripulação de uma empresa que opera no sistema de transporte público, uma sequência de jornadas diárias de trabalho para um dado horizonte de planejamento. Este sequenciamento deve atender uma série de restrições legais e operacionais, ao mesmo tempo em que busca equilibrar a carga de trabalho e ainda minimizar o total de tripulações necessárias na operação. Desta maneira, ao resolver o PRT procura-se minimizar os custos fixos e variáveis com a mão de obra da empresa e manter um ambiente saudável de trabalho entre as tripulações.

O planejamento do sistema de transporte público urbano é uma tarefa delicada e que envolve tanto o poder público quanto as empresas responsáveis pela prestação do serviço de transporte público. Devido à complexidade deste planejamento, ele está dividido nas seguintes etapas: a definição das linhas com suas trajetórias; a criação do quadro de horários; a programação dos veículos; a programação das tripulações; e o rodízio das tripulações. A definição das linhas e a determinação do quadro de horários são de responsabilidade do poder público, enquanto a programação dos veículos e tripulações, assim como o rodízio das tripulações fica a cargo das empresas de transporte público. As etapas realizadas pelo poder público levam em consideração critérios de demanda pelo serviço da infraestrutura das vias urbanas. Por outro lado, o planejamento das empresas de transporte deve minimizar o custo operacional, atendendo às normas impostas quanto ao nível de qualidade do serviço e à satisfação dos usuários (Silva, 2001).

A primeira etapa do planejamento do sistema de transporte público consiste em definir quais são as linhas em operação, com os seus respectivos percursos. Em seguida deve-se criar o quadro de horário, estipulando para cada linha os horários de partida de suas viagens. Estas duas etapas são de responsabilidade do poder público e visam atender à demanda de forma racional e de acordo com a infraestrutura disponível.

Após estabelecer o quadro de horários, o restante do planejamento fica a cargo das empresas, sendo que nesta etapa o primeiro problema consiste em determinar o número de veículos 
necessário para cumprir o quadro de viagens e quais as viagens realizadas por cada veículo. Definida a programação dos veículos, é necessário realizar a programação das tripulações. Este problema consiste em definir um conjunto de jornadas diárias de trabalho tal que cada veículo tenha sua operação realizada com sucesso e o custo da mão de obra seja mínimo. Ao final desta etapa estarão definidas as frotas e as jornadas para os dias úteis, os sábados e os domingos (Daduna e Paixão, 1995; Silva et al. 2007a, Silva et al. 2007b, Souza et al. 2006).

$\mathrm{Na}$ última etapa deve ser estabelecido o rodízio das tripulações, ou a escala dos condutores, problema abordado neste trabalho. O problema do rodízio de tripulações (PRT) é muito estudado e desenvolvido para a área de transporte aeroviário, devido ao seu impacto nos custos da operação. Uma outra área de grande aplicação é o setor de transporte público ferroviário e metroviário, que assim como no setor aeroviário, divide o problema nas etapas de geração e otimização das jornadas diárias, e posteriormente faz o rodízio das tripulações (Ernst et al., 2004a). Ernst et al. (2004a) destacam que Bodin et al. (1983) e Carraresi e Gallo (1984) representam os principais trabalhos que abordam o PRT no sistema de transporte público. Entretanto, o interesse pela resolução apenas da etapa diária do problema prevalece ainda hoje, conforme observado por Ernst et al. (2004a) e Ernst et al. (2004b).

O modelo de escalonamento cíclico é usado para a classe de problemas de trabalhadores com localização fixa e pode ser aplicado a determinados problemas de rodízio (Bodin et al. 1983). Tal modelo considera todas as jornadas de um dado dia com pesos iguais, o que em determinadas situações não ocorre. O objetivo típico para o rodízio no sistema de transporte público é balancear o trabalho requerido entre todas as tripulações, considerando que cada tripulação recebe o mesmo pagamento independentemente do trabalho executado. Neste caso, o objetivo é produzir rodízios individuais resultando em um plano global de trabalho o mais equânime possível em termos do total de horas trabalhadas ao longo do período (Baker 1974, apud Bodin et al. 1983).

Carraresi e Gallo (1984) apresentam um modelo no qual a cada jornada é atribuído um peso, que representa uma medida do custo da jornada para a tripulação. Tal peso pode ser dado em função de: i) duração da jornada, ii) atratividade da jornada, iii) tempo gasto pela tripulação para se deslocar da garagem até o ponto onde a jornada se inicia, entre outros. O problema de se encontrar um conjunto de jornadas balanceadas ao longo de um horizonte de planejamento é formulado por meio do seguinte problema de gargalo: minimizar a soma dos pesos das 
jornadas designadas à tripulação que tem a pior configuração. Para este problema, os autores apresentam uma heurística que encontra uma solução subótima. É apresentado um algoritmo para o problema de designação com gargalo, o qual é utilizado como subrotina para resolver o problema do rodízio das tripulações.

Deve ficar claro que nenhuma das abordagens descritas anteriormente fornece uma solução completa para o problema do rodízio das tripulações. A função objetivo apresentada por Bodin et al. (1983) não é realista e o modelo de Carraresi e Gallo (1984) mantém as folgas fixas no final de semana, não prevendo atividades para os sábados, domingos e feriados. Os modelos apresentados não são facilmente ampliáveis para horizontes mais amplos, mas podem ser úteis quando combinados com procedimentos que tratam de outros aspectos do problema.

Bianco et al. (1992) formulam o PRT através de um modelo de programação linear inteira e descrevem uma heurística que utiliza o limitante inferior, proveniente da formulação matemática, para reduzir as dimensões do problema. A cada iteração o algoritmo resolve um problema de designação multinível com gargalo, para o qual é proposto um novo procedimento que produz soluções que convergem assintóticamente para o ótimo.

Yunes (2000) abordou o PRT utilizando técnicas de Programação Matemática e de Programação por Restrições. Para o PRT foi desenvolvido um algoritmo híbrido de geração de colunas combinando as duas técnicas mencionadas. Foram utilizadas duas metodologias para resolver esse problema. Na primeira abordagem, o problema é modelado como um problema de programação linear inteira, e resolvido com a técnica de branch and bound. A segunda abordagem se baseia em programação por restrições. A primeira abordagem só é aplicável a problemas de pequeno porte, e ainda se mostrou menos eficaz do que a técnica Programação por Restrições.

Além de haver poucos trabalhos sobre o PRT do sistema de transporte público, a prática de manter as tripulações nas mesmas jornadas ao longo do período não é uma boa estratégia pois produzem soluções com grande quantidade de horas extras e ociosas devido ao fator cumulativo do processo. Principalmente quando é permitido o sistema de banco de horas de trabalho, onde as horas extras podem ser compensadas com horas de ociosas dentro do 
horizonte de planejamento. Nesse sentido torna-se fundamental estudar o PRT e propor métodos para a resolução de problemas práticos.

Neste trabalho o PRT é resolvido em duas etapas. Na primeira etapa é gerada uma sequência de jornadas diárias sem a preocupação de satisfazer as restrições das folgas legais. A solução é obtida resolvendo uma sequencia de problemas de designação para as jornadas diárias. Desta forma, no primeiro dia do horizonte as jornadas são atribuídas de forma sequencial às tripulações da empresa. A partir daí as jornadas a serem atribuídas às tripulações no próximo dia são definidas resolvendo um modelo de designação, que tem como objetivo minimizar as quantidades acumuladas de horas extras considerando as diferentes possibilidades de compensação com horas ociosas no dia seguinte. Na segunda etapa são auferidas as folgas que se fizerem necessárias. Para tanto, é proposto um modelo de programação linear inteira para completar as folgas às tripulações ainda não atribuídas naturalmente na etapa anterior. Em situações onde o número médio de veículos em operação nos finais de semana é menor ou igual $50 \%$ é possível conceder folgas nos sábados e domingos a todas as tripulações sem a necessidade de contratar outros motoristas. Esta é a situação considerada na literatura uma vez que o problema não trata das folgas. A necessidade de se contratar tripulações do tipo "folguistas" faz parte da realidade brasileira e surge com o aumento no número de viagens nos finais de semana. Assim, é proposto o segundo modelo que considera as folgas já existentes nos sábados e domingos e acrescenta um folguista sempre que for necessário dar uma folga a uma tripulação em um dia da semana. Este modelo é uma contribuição deste trabalho e tem como objetivo minimizar o número máximo de duplas do tipo folguista contidas na escala.

Os modelos apresentados neste trabalho foram testados com dados reais de duas empresas que operam em Belo Horizonte e as soluções foram comparadas com a escala das empresas. A primeira empresa forneceu os dados da escala realizada ao longo de um período de cinco semanas. Entretanto, a comparação do resultado do modelo com a solução adotada pela empresa é prejudicada devido a fatores exógenos que ocorreram no período como: i) o início das férias de alguns motoristas; ii) demissões; iii) faltas ou licenças por motivo de saúde, entre outros. Desta forma, foi incluída neste estudo uma segunda empresa que forneceu os dados da programação da escala de seus motoristas. Esta empresa tem uma programação semanal que se repete ao longo do mês e conta com um conjunto específico de motoristas folguistas para completar as folgas exigidas por lei. 
O presente trabalho está organizado da seguinte maneira: A próxima seção apresenta os dados de entrada do problema de rodízio das tripulações, ou seja, as jornadas diárias de trabalho, descrevendo as características relevantes para o rodízio das tripulações. Em seguida, a Seção 2 trata do sequenciamento das jornadas diárias de trabalho e a formulação do rodízio de tripulações como uma sequencia de problemas de fluxo em redes. A Seção 3 apresenta o modelo de programação linear inteira proposto para alocar os folguistas. Os resultados são discutidos na Seção 4 e na última seção são apresentas as conclusões do trabalho.

\section{Jornadas Diárias de Trabalho}

O Problema de Rodízio das Tripulações tem como dados de entrada as leis trabalhistas, as regras operacionais da empresa e as jornadas diárias a serem executadas ao longo do período de planejamento. Estas jornadas são consideradas iguais para todos os dias úteis, diferindo nos sábados e domingos. Estes três conjuntos de jornadas são denominados jornadas diárias e, em geral, o número de jornadas nos dias úteis é maior do que o número de jornadas dos sábados, que por sua vez é maior do que o número de jornadas nos domingos. Esta característica facilita a alocação das folgas previstas na lei, mas pode não solucionar completamente este problema. Abaixo estão relacionadas as principais características das jornadas diárias utilizadas no modelo de rodízio das tripulações desenvolvido neste trabalho.

i. Número de identificação: número inteiro que está associado univocamente a uma determinada jornada diária de trabalho.

ii. Horário de início: instante em que a jornada se inicia, ou seja, o horário de partida da primeira viagem da jornada.

iii. Horário de término: hora em que a jornada se encerra, isto é, o horário de chegada da última viagem da jornada.

iv. Ociosidade: quando uma jornada tem duração inferior à carga normal de trabalho, então a ociosidade é a carga normal de trabalho menos a duração da jornada.

v. Hora extra: quando uma jornada tem duração superior à carga normal de trabalho, então a hora extra é igual à duração da jornada menos a carga normal de trabalho.

vi. Dupla pegada: indica se a jornada apresenta uma interrupção nas suas atividades maior do que duas horas.

vii. Turno: indica o turno em que a jornada se inicia. 
viii. Noturna: indica se a jornada é do tipo noturno. Normalmente a remuneração por hora trabalhada durante o horário noturno é maior do que no horário convencional.

Uma jornada é do tipo dupla pegada quando há um intervalo entre duas viagens superior a duas horas, intervalo este que não é remunerado. Nesta abordagem, as tripulações que realizam jornadas do tipo dupla pegada e aquelas que operam em jornadas noturnas têm direito a folgar nos domingos, regra esta que não se aplica às jornadas normais. Neste trabalho a carga diária normal de trabalho é de seis horas e quarenta minutos. $\mathrm{O}$ dia foi dividido em quatro turnos, cada um com seis horas de duração. O primeiro turno compreende o intervalo que vai das 04:00 às 09:59, o segundo de 10:00 às 15:59 e assim sucessivamente. Foram consideradas noturnas, as jornadas cujo início se dá entre as 22:00 e 05:00 horas.

\section{Rodízio das Tripulações}

Conforme visto anteriormente, cada jornada apresenta um conjunto de atributos particulares que devem ser considerados durante o seu sequenciamento. Neste sentido, ao definir uma escala mensal de trabalho devem ser consideradas tanto restrições de ordem legal, quanto as regras operacionais adotadas pela empresa. Estas restrições são apresentadas a seguir.

i. O horizonte de planejamento sempre inicia na segunda-feira.

ii. O tempo mínimo entre o término de uma jornada e o início da próxima jornada deve ser maior ou igual a 11 horas.

iii. Nenhuma tripulação pode trabalhar mais de seis dias consecutivos sem uma folga.

iv. Dentro de uma mesma semana, as tripulações devem executar jornadas dos dias úteis pertencentes ao mesmo turno de trabalho. Exceto para duplas pegadas ou noturnas.

v. As tripulações que cumprem jornadas do tipo dupla pegada ou noturna têm o direito de folgar todos os domingos do horizonte de planejamento.

vi. Dentro do horizonte de planejamento, considerado de cinco semanas, todas as tripulações têm direito a pelo menos uma folga no domingo.

vii. No decorrer de todos os dias do horizonte de planejamento as tripulações cumprem somente um dos tipos de jornada: i) simples ou ii) duplas pegadas ou noturnas, podendo intercambiar entre dupla pegada e noturna.

viii. Nos finais de semana e feriados é permitido desprezar as restrições de turno de 
trabalho e de dupla pegada ou noturno.

ix. São gerados rodízios para uma semana que posteriormente podem ser alternados ao longo do horizonte de planejamento.

x. As horas extras que uma tripulação faz em uma jornada podem ser compensadas com horas ociosas de outra jornada desde que ocorram dentro do horizonte de planejamento.

A sequência das jornadas realizadas por uma dada tripulação é denominada como o rodízio da tripulação. O modelo implementado neste trabalho segue a mesma ideia de Carraresi e Gallo (1984), considerando características particulares da realidade do caso abordado. Assim, a partir dos dados do primeiro dia do horizonte, onde cada rodízio $i$ realiza a jornada $i$, é construída uma rede bipartida e resolvido um problema de designação para fazer a alocação do segundo dia do horizonte. Este modelo minimiza o total de horas extras tentando compensá-las com horas ociosas. Neste trabalho o rodízio mensal das tripulações foi dividido em duas etapas: i) geração do rodízio semanal e ii) criação do rodízio mensal com o sequenciamento otimizado dos rodízios semanais.

\subsection{Rodízio Semanal}

Um rodízio semanal é uma sequência de jornadas de trabalho que deve ser cumprida por uma mesma tripulação ao longo de uma semana, isto é, iniciando na segunda-feira e encerrando no domingo. O rodízio semanal é construído pela sequência de jornadas diárias à medida que elas são designadas pelo modelo. Portanto, cada rodízio deve armazenar uma série de informações referentes às jornadas atribuídas a ele até a iteração corrente. As informações caracterizam o tipo de jornadas presentes no rodízio e a distribuição das jornadas. Entre essas características incluem:

i. Número de identidade: número inteiro associado univocamente a um rodízio semanal.

ii. Sequência de jornadas: armazena a sequência das jornadas atribuídas ao rodízio.

iii. Horário de início: horário de início da primeira jornada atribuída ao rodízio.

iv. Horário de término: horário de término da última jornada atribuída ao rodízio.

v. Ociosidade: soma dos tempos de ociosidade de todas as jornadas atribuídas ao rodízio.

vi. Hora extra: soma das horas extras de todas as jornadas atribuídas ao rodízio semanal.

vii. Dupla pegada ou Noturno: indica se as jornadas de trabalho presentes no rodízio são 
do tipo dupla pegada ou noturno.

viii. Turno: indica o turno das jornadas presentes no rodízio.

Inicialmente, para o primeiro dia da semana, que corresponde à segunda-feira, atribui-se a cada rodízio $i$ a jornada diária $i \operatorname{com} i=1 \ldots n$, onde $n$ representa o número de jornadas diárias de trabalho. Do segundo dia em diante, para cada dia $k$, constrói-se uma rede conforme a Figura 1.

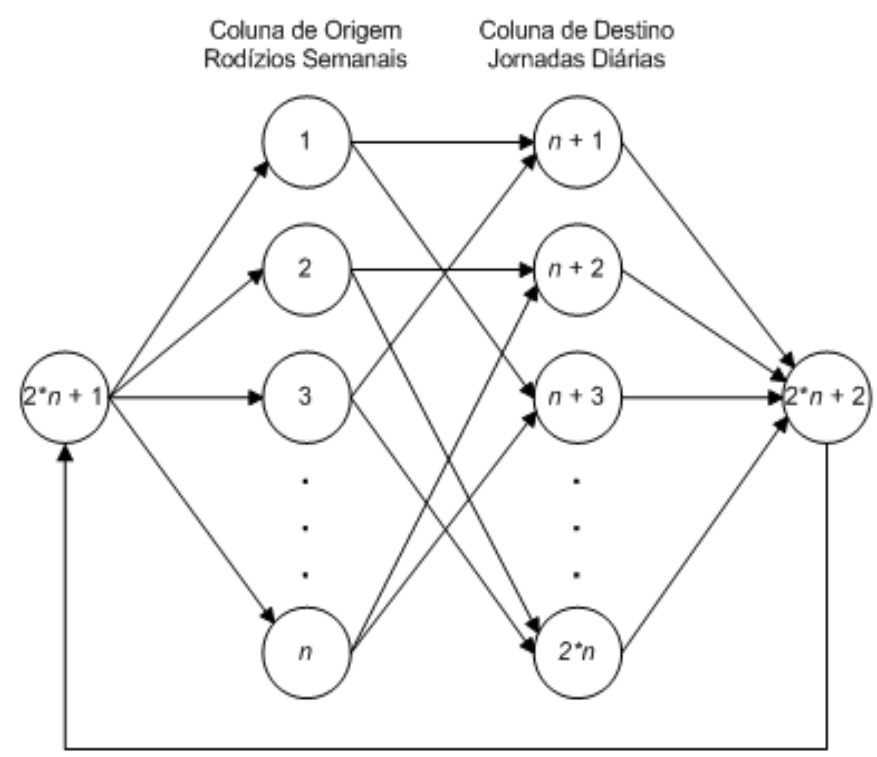

Figura 1 - Topologia da rede.

A rede bipartida que define a atribuição das jornadas a serem executadas no dia $k+1$ a partir dos rodízios já estabelecidos até o dia $k$ é construída de acordo com as seguintes regras:

a) um arco $a_{i j} \in A$ representa a possibilidade do rodízio $i$ (aquele que executa a jornada $i$ no dia 1) fazer a jornada $j$ no dia $k+1$. Este arco só é criado se todas as restrições forem satisfeitas ao combinar a jornada realizada pelo rodízio $i$ no dia $k$ com a jornada $j$ do dia $k+1$. O limite inferior deste arco é igual a zero e o limite superior é igual a 1.

b) O custo $c_{i j}$ associado ao arco $a_{i j}$ é dado por:

$$
c_{i j}=\left|c_{1}+c_{2}\right|+\text { Custo-Extra }
$$

Onde:

$c_{l}=$ diferença entre o número de horas extras e de horas ociosas acumuladas no rodízio $i$. 
$c_{2}=$ diferença entre o número de horas extras e de horas ociosas referentes à jornada $j$.

A definição de $c_{1}$ e $c_{2}$ contempla tanto jornadas com ociosidade quanto jornadas com horas extras e permite: i) acumular horas extras, caso ambas as jornadas tenham horas extras, ii) acumular ociosidade, caso ambas tenham ociosidade e, iii) compensar horas extras do rodízio $i$ com a ociosidade da jornada $j$ e vice-versa.

Custo-Extra = penalização para determinadas características viáveis indesejáveis contidas na solução. Neste caso o Custo-Extra é constituído de duas parcelas: uma que penaliza atribuir uma jornada de trabalho em um domingo a uma tripulação que faz dupla pegada ou noturno durante os dias úteis, e outra que penaliza as soluções nas quais uma mesma tripulação folga no sábado e no domingo da mesma semana.

c) a variável de decisão $x_{i j}$ assume o valor 1 caso o arco $a_{i j}$ seja utilizado na solução e 0 caso contrário.

O problema de designação é resolvido transformando-o em um problema de circulação, conforme a Figura 1, e aplicando-se o algoritmo out-of-kilter (Ahuja et al. 1993). Para tanto são acrescentados à rede nós e arcos auxiliares, que são: a) o nó $2 n+1$ que é a origem de $n$ arcos de oferta; b) o nó $2 n+2$ que é o destino de $n$ arcos de demanda; c) $n$ arcos ligando o nó $2 n+1$ aos $n$ nós dos rodízios já definidos até o dia $k$, com custo zero, limite inferior e limite superior iguais a um; d) $n$ arcos ligando cada um dos $n$ nós, correspondentes às jornadas a serem executadas no dia $k+1$, ao nó de destino $2 n+2$. Estes arcos têm custo zero, limite inferior e superior iguais a um; e) um arco de retorno ligando o nó $2 n+2$ ao nó $2 n+1$ com custo zero, limite inferior e superior iguais a $n$, forçando a formação de ciclos. O modelo matemático referente ao problema de circulação fica da forma que segue.

$$
\begin{array}{cc}
\operatorname{Min} \sum_{(i, j) \in A} c_{i j} x_{i j} & \text { sujeito a } \\
\sum_{(i, j) \in A} x_{i j}-\sum_{(j, i) \in A} x_{j i}=0 & \forall i \in\{1,2, \ldots 2 n+2\} \\
l_{i j} \leq x_{i j} \leq u_{i j} & \forall(i, j) \in A
\end{array}
$$


Para os arcos originais, a variável de decisão $x_{i j}=1$ se a jornada $j$ for executada pelo rodízio que iniciou o primeiro dia do horizonte com a jornada $i$ e $x_{i j}=0$ caso contrário. A expressão (2) minimiza o custo total, a restrição (3) garante o equilíbrio de fluxo nos nós, enquanto (4) assegura que cada jornada será executada por um único rodízio. A partir da solução deste modelo é possível definir qual é o rodízio responsável por cada jornada a ser executada no dia $k+1$ de forma que o custo total seja mínimo. Este procedimento se repete até que todas as jornadas de uma mesma semana sejam atribuídas ao algum rodízio semanal. Finalmente repete-se o mesmo procedimento de geração do rodízio semanal tantas vezes quanto for o número de semanas com diferentes características, caso ocorram feriados no período.

\subsection{Rodízio Mensal}

Um rodízio mensal compreende uma sequência de rodízios semanais que deve ser cumprida por uma mesma tripulação durante o período de planejamento, que, apesar de ser denominado "mensal" costuma conter entre quatro e sete semanas.

A construção do rodízio mensal é feita de forma análoga à geração dos rodízios semanais, ou seja, através do modelo de designação apresentado na subseção anterior. A diferença é que nesta fase os nós da coluna de origem formam os rodízios mensais enquanto os nós da coluna de destino representam os rodízios semanais. Assim, para a primeira semana do horizonte de planejamento, atribui-se o rodízio semanal $i$ ao rodízio mensal $i, \operatorname{com} i=1, \ldots, n$, onde $n$ é o número de rodízios semanais criados pelo procedimento descrito na Subseção 2.1.

Durante a geração do rodízio mensal, o cálculo do custo nos arcos também é semelhante ao efetuado na etapa do rodízio semanal. A forma da equação se mantém a mesma apresentada em (1), alterando somente o significado dos termos. Desta forma temos:

$c_{1}=$ diferença entre o número de horas extras e horas ociosas acumuladas no rodízio mensal $i$.

$c_{2}=$ diferença entre o número de horas extras e horas ociosas referentes ao rodízio semanal $j$.

CustoExtra $=$ penalidade para os arcos que ligam um rodízio semanal que contém folga no domingo ao rodízio mensal de uma tripulação que não realiza jornadas do tipo dupla pegada ou noturna e que já fora contemplada com uma folga no domingo. Este CustoExtra tem como objetivo reduzir o número de tripulações do tipo folguista (ver Seção 3) que devem ser 
adicionados posteriormente à solução em virtude da restrição legal que impõe que toda tripulação tem direito a pelo menos uma folga no domingo a cada cinco semanas.

\section{O Problema de Distribuição das Folgas}

Durante o sequenciamento das jornadas diárias de trabalho, descritas anteriormente, foi permitido que as tripulações trabalhassem mais de seis dias consecutivos apesar desta prática infringir a legislação. O modelo também não contemplou o direito das tripulações terem pelo menos uma folga no domingo dentro do horizonte de planejamento (restrições iii. e vi da Seção 2). Estas restrições foram ignoradas, pois o modelo de designação não é capaz de representá-las. Tais inviabilidades foram corrigidas por meio de um segundo modelo de programação inteira responsável pelo acréscimo e a alocação de um segundo tipo de tripulação denominada folguista. Os folguistas são tripulações que trabalham para cobrir as jornadas de trabalho de uma tripulação "regular" quando esta estiver gozando o seu direito a um dia de folga. O modelo de programação inteira proposto neste trabalho para resolver o problema de alocação dos folguistas é descrito a seguir.

\section{Conjunto dos dados de entrada:}

$R=$ Conjunto de todos os rodízios $r$ do PRT. Este conjunto varia de 1 até $n$, onde $n$ é o número de rodízios existentes, que corresponde ao número de jornadas dos dias úteis.

$D=$ Conjunto de todos os dias $d$ do horizonte de planejamento. Este conjunto varia de $1 \mathrm{a} \mathrm{m}$, onde $m$ é o número de dias do horizonte de planejamento.

$D_{q}=$ Conjunto dos $m-q$ primeiros dias do horizonte de planejamento, onde $q$ representa o número máximo de dias consecutivos que uma tripulação pode trabalhar sem folgar. Conjunto usado para garantir pelo menos uma folga a cada $q+1$ dias de trabalho.

Dom = Subconjunto de $D$ que contém somente os domingos do horizonte de planejamento.

$X_{r, d}=$ Matriz binária que tem valor 1 na posição $(r, d)$ caso a tripulação $r(r \in R)$ folgue naturalmente no dia $d,(d \in D)$ e 0 caso contrário. É um dado de entrada para o problema de distribuição dos folguistas obtido a partir do resultado do sequenciamento de jornadas 
realizado na etapa anterior. É evidente que, como não há folgas nos dias úteis $X_{r, d}$ é sempre zero para os valores de $d$ que representam os dias úteis.

$S_{r, d q}=$ Matriz inteira que armazena a soma de $q+1$ dias consecutivos do horizonte de planejamento, onde $r \in R$ e $d q \in D_{q}$. Esta matriz é um dado de entrada que permite agilizar os cálculos durante a resolução do modelo. Ela representa o número de folgas "naturais" existentes em $q+1$ dias consecutivos. Matematicamente, $S_{r, d q}$ é uma soma móvel dada pela expressão (5) a seguir.

$$
S_{r, d q}=X_{r, d}+X_{r, d+1}+\ldots+X_{r, d+q}
$$

Conjunto de variáveis:

$Y_{r, d}=$ Trata-se de uma matriz binária que recebe o valor 1 caso seja necessário alocar um folguista para cobrir a jornada do rodízio $r(r \in R)$ no dia $d(d \in D)$, e 0 caso contrário.

$C=$ Variável auxiliar que representa o número máximo de folguistas dentre todos os dias do horizonte de planejamento.

O modelo de programação linear inteira fica da seguinte forma:

$$
\begin{array}{cc}
\text { Min } Z=P_{1} \times C+P_{2} \times \sum_{r \in R} \sum_{d \in D} Y_{r, d}+P_{3} \times \sum_{r \in R} \sum_{d o \in \text { Dom }} Y_{r, d o} & \text { sujeito a } \\
\sum_{r \in R} Y_{r, d} \leq C, & \forall d \in D \\
S_{r, d q}+\sum_{i=0}^{q} Y_{r, d q+i} \geq 1, & \forall r \in R, \forall d q \in D_{q} \\
\sum_{d \in D o m}\left(X_{r, d}+Y_{r, d}\right) \geq 1, & \forall r \in R \\
Y_{r, d} \in\{0,1\}, & \forall r \in R, \forall d \in D
\end{array}
$$

A função objetivo (6) minimiza a combinação linear do número máximo de folguistas dentre todos os dias do horizonte com o total de folguistas e em especial os folguistas dos domingos, multiplicados pelos seus respectivos pesos $P_{1}, P_{2}$ e $P_{3}$. Em (7) fica expresso que $C$ é o número 
máximo de folguistas necessários dentre todos os dias do horizonte de planejamento. A restrição (8) impede que qualquer tripulação trabalhe mais de $q$ dias consecutivos sem uma folga. A expressão (9) garante que toda tripulação tem o direito de folgar pelo menos um domingo dentro do horizonte de planejamento, e em (10) tem-se que a variável de decisão $Y_{r, d}$ é uma variável do tipo zero ou um.

Apesar do modelo de programação linear inteiro, descrito nas equações de (6) a (10), ser aparentemente simples em situações práticas o número de restrições e de variáveis é muito elevado. Por este motivo, foi utilizado um computador com grande capacidade de processamento e espaço de memória RAM para possibilitar a obtenção do ótimo global. Esse modelo é uma combinação de um modelo de otimização do tipo gargalo (bottleneck model) com um modelo de recobrimento de conjuntos (set covering model).

\section{Apresentação e Análise dos Resultados Computacionais}

O algoritmo out-of-kilter e os procedimentos para a construção das redes de designação utilizados no modelo proposto foram implementados na linguagem $\mathrm{C} / \mathrm{C}++$ utilizando o ambiente de desenvolvimento integrado Microsoft Visual C++ 2008 Express Edition e testados em um computador com processador Intel i7 3.1 GHz e 8GB de memória RAM, sob o sistema operacional Windows 7 Professional de 64 bits. O modelo de programação linear utilizado na distribuição dos folguistas foi desenvolvido no software LINGO 8.0.

Foram realizados testes computacionais com dados reais de duas empresas que operam na cidade de Belo Horizonte - MG. Os dados fornecidos pelas empresas diferem quanto à sua natureza. A Empresa A forneceu os dados da escala realizada no período de cinco semanas sem feriados. Estes dados carregam problemas de absenteísmo que ocorrem na operação diária envolvendo mais de uma centena de funcionários. Por outro lado, a Empresa B forneceu a programação da escala. As empresas do setor mantem um grupo de motoristas de plantão e outro no regime de sobreaviso para suprir as faltas que podem ocorrem no dia-a-dia. 


\subsection{Testes com os dados da Empresa A}

Os dados fornecidos pela Empresa A referem-se à escala realizada em cinco semanas com início em uma segunda-feira e término em um domingo, sem a ocorrência de feriados. A Tabela 1 mostra as principais características dos dados de entrada utilizados nos testes. Na Tabela 1 é apresentado o número de motoristas para cada tipo de dia, onde cada motorista corresponde a uma jornada, as horas extras e as horas ociosas de cada tipo de dia. As jornadas a serem realizadas nos dias úteis, sábados e domingos são conhecidas em detalhe. Desta maneira, os dados de entrada apresentam 104 jornadas, das quais 4 são do tipo dupla pegada e 13 são do tipo noturna. A soma das horas extras referente a cada dia útil é de 62 horas e 46 minutos. Da mesma forma, o total de ociosidade é de 78 horas e 36 minutos. O mesmo tipo de informação é apresentado para os sábados e os domingos do horizonte a ser planejado. $\mathrm{O}$ principal objetivo do primeiro modelo é compensar as jornadas com horas extras com jornadas que contém ociosidade ao longo dos dias do período balanceando assim a carga de trabalho dos motoristas.

\section{Tabela 1 - Caracterização dos dados de entrada da Empresa A}

\begin{tabular}{|c|c|c|c|c|c|}
\hline Tipo de Dia & Motoristas & Dupla pegada & Noturno & Horas extras & Ociosidade \\
\hline Dia Útil & 104 & 4 & 13 & $62: 46$ & $78: 36$ \\
\hline Sábado & 70 & 11 & 0 & $45: 37$ & $26: 54$ \\
\hline Domingo & 53 & 9 & 0 & $27: 41$ & $16: 01$ \\
\hline
\end{tabular}

Nos testes realizados, foram consideradas apenas as jornadas dos motoristas, pois estes são responsáveis por retirar o veículo da garagem no início da operação e retornar com o veículo à garagem no final da operação. Os resultados obtidos através dos modelos propostos neste trabalho foram comparados com os dados da operação da empresa, no período mencionado e são apresentados na Tabela 2.

Tabela 2 - Comparação dos resultados obtidos com os dados da Empresa A

\begin{tabular}{|l|c|c|c|}
\hline & Total de Motoristas & Horas extras & Ociosidade \\
\hline Modelo Proposto & 111 & $613: 42$ & $417: 08$ \\
\hline Escala Realizada & 244 & $1.106: 39$ & $1.695: 52$ \\
\hline
\end{tabular}


Os dados apresentados na Tabela 2 mostram que a aplicação do modelo permitiu uma redução na ordem de $54,5 \%$ no número de motoristas, de $44,54 \%$ no total de horas extras e de $75,4 \%$ no total de horas ociosas, o que está muito acima do esperado.

Analisando dos dados fornecidos pela empresa é possível observar que há um grande número de motoristas que trabalham apenas alguns dias no período considerado. A empresa justificou que esta grande diferença existente entre as soluções se deve a período de férias, demissões, faltas por motivo de saúde, entre outros. Desta forma, os dados da empresa foram filtrados considerando apenas os motoristas que trabalharam pelo menos $k$ dias do período, para $k$ variando entre 6 e 13 dias. Os dados com tais características são apresentados na Tabela 3.

Tabela 3 - Comparação com dados da empresa considerando tempo mínimo de trabalhado

\begin{tabular}{|l|c|c|c|}
\hline & Motoristas & Horas extras & Ociosidade \\
\hline Modelo Proposto & 111 & $613: 42$ & $417: 08$ \\
\hline Pelo menos 6 dias trabalhados & 143 & $988: 48$ & $1.624: 27$ \\
\hline Pelo menos 7 dias trabalhados & 136 & $967: 57$ & $1.579: 13$ \\
\hline Pelo menos 10 dias trabalhados & 120 & $918: 45$ & $1.482: 57$ \\
\hline Pelo menos 11 dias trabalhados & 118 & $907: 29$ & $1.481: 37$ \\
\hline Pelo menos 12 dias trabalhados & 112 & $861: 48$ & $1.431: 12$ \\
\hline Pelo menos 13 dias trabalhados & 109 & $844: 23$ & $1.431: 12$ \\
\hline
\end{tabular}

Os dados na Tabela 3 mostram que mesmo eliminando motoristas que trabalharam no mínimo entre 6 e 12 dias na escala, a solução obtida pelo modelo ainda é superior. Somente quando são considerados os motoristas que trabalham pelo menos 13 dias do período é que a solução da empresa apresenta um número menor de motoristas. Mesmo assim, o número de horas extras da solução otimizada é $27,37 \%$ inferior à solução da empresa.

Uma outra característica que chama a atenção nos dados fornecidos pela empresa diz respeito ao número médio de horas ociosas por dia. Determinados motoristas apresentam ociosidade acima de duas horas por dia. Tal fato levou a uma segunda filtragem dos dados da empresa, combinando o número mínimo de dias trabalhados com ociosidade máxima por dia. Os resultados após esta redução na solução da empresa são apresentados na Tabela 4. 
Tabela 4 - Dados da empresa considerando tempo mínimo trabalhado e ociosidade máxima

\begin{tabular}{|l|c|c|c|}
\hline & Motoristas & Horas extras & Ociosidade \\
\hline Modelo Proposto & 111 & $613: 42$ & $417: 08$ \\
\hline Ociosidade máxima de 2 hs/dia & 215 & $1.106: 39$ & $197: 34$ \\
\hline $\begin{array}{l}\text { Oc. máxima de 2 hs/dia e pelo menos 6 dias de } \\
\text { trabalho }\end{array}$ & 120 & $988: 48$ & $151: 28$ \\
\hline $\begin{array}{l}\text { Oc. máxima de 2 hs/dia e pelo menos 7 dias de } \\
\text { trabalho }\end{array}$ & 115 & $967: 57$ & $148: 51$ \\
\hline $\begin{array}{l}\text { Oc. máxima de 2 hs/dia e pelo menos 8 dias de } \\
\text { trabalho }\end{array}$ & 107 & $933: 46$ & $139: 09$ \\
\hline
\end{tabular}

Neste caso, ao considerar os motoristas que apresentam ociosidade máxima de 2 horas por dia, a solução fornecida pelo modelo ainda é significativamente melhor do que a solução realizada pela empresa, com uma redução de 48,37\% no número de motoristas e de 44,58\% no total de horas extras pagas pela empresa. Somente ao considerar ociosidade máxima de 2 horas por dia e pelo menos 8 dias de trabalho dentro do período é que a solução da empresa apresenta o número de motoristas inferior ao número de motoristas fornecido pelo modelo. Mas, ainda assim, o total de horas extras da solução otimizada apresenta uma redução de $52,2 \%$ em relação ao total de horas extras da escala da empresa.

\subsection{Testes com os dados da Empresa B}

A Empresa B forneceu os dados da escala programada para uma semana, desta forma foi possível fazer uma comparação mais precisa entre a solução produzida pela empresa e a solução obtida com o modelo. Nesta empresa é realizada a escala semanal que posteriormente é repetida para as semanas seguintes. A empresa conta com um conjunto de motoristas específicos para cobrir as folgas dos motoristas "titulares". Os motoristas folguistas não se mantêm no mesmo turno ao longo da semana e tem o mesmo regime de folga dos motoristas que fazem jornadas normais. 
A Tabela 5 contém um resumo das jornadas diárias da empresa que são os dados de entrada para o modelo de otimização. Assim como no caso anterior são apresentados o número de motoristas para cada tipo de dia, o tipo das jornadas, o total de horas extras e de horas ociosas.

Tabela 5 - Caracterização dos dados de entrada da Empresa B

\begin{tabular}{|c|c|c|c|c|c|}
\hline Tipo de Dia & Motoristas & Dupla pegada & Noturno & Horas extras & Ociosidade \\
\hline Dia Útil & 279 & 21 & 44 & $246: 16$ & $38: 52$ \\
\hline Sábado & 213 & 0 & 42 & $141: 52$ & $75: 01$ \\
\hline Domingo & 148 & 0 & 27 & $104: 32$ & $41: 48$ \\
\hline
\end{tabular}

Neste caso a possibilidade de compensar as horas extras com as horas ociosas diminui consideravelmente em relação à Empresa $\mathrm{A}$, uma vez que a quantidade de horas ociosas representa aproximadamente $15,85 \%$ da quantidade de horas extras contidas nas jornadas dos dias úteis. Para a escala de uma semana a empresa emprega 319 motoristas contendo um total de 1.339:58 horas extras e 131:58 horas ociosas, sendo que do total de motoristas, 19 são folguistas. Como a escala se repete a cada semana, ao final de cinco semanas a empresa totaliza 6.699:50 horas extras e 659:50 horas ociosas com os mesmos 319 motoristas.

Para esta empresa foram conduzidos dois testes distintos. No primeiro teste foi resolvido o problema de rodízio das tripulações para o período de uma semana e o resultado foi comparado com os dados fornecidos pela empresa. A Tabela 6 apresenta as características da solução obtida pelo modelo, assim como da solução adotada pela empresa.

\section{Tabela 6 - Rodízio semanal obtido pelo modelo e a solução da Empresa B}

\begin{tabular}{|l|c|c|c|}
\hline & Total de Motoristas & Horas extras & Ociosidade \\
\hline Modelo Proposto & 304 & $1.165: 50$ & $00: 00$ \\
\hline Escala Realizada & 319 & $1.339: 58$ & $131: 58$ \\
\hline
\end{tabular}

Os resultados mostram que houve uma redução de 4,70\% no número de motoristas, 12,99\% no número de horas extras e ainda foram eliminadas as horas ociosas dos motoristas da empresa. 
No segundo cenário o modelo foi executado para o período de cinco semanas e o resultado foi comparado com a solução da empresa, considerando que a empresa utiliza a mesma escala em todas as semanas.

\section{Tabela 7 - Rodízio obtido para cinco semanas e a solução da Empresa B}

\begin{tabular}{|l|c|c|c|}
\hline & Total de Motoristas & Horas extras & Ociosidade \\
\hline Modelo Proposto & 292 & $5.829: 10$ & $00: 00$ \\
\hline Escala Realizada & 319 & $6.699: 50$ & $659: 50$ \\
\hline
\end{tabular}

Para este caso foi verificada uma redução de 8,46\% no número de motoristas e de $13,00 \%$ nas horas extras com a eliminação da ociosidade dos motoristas. A redução nas horas extras se mantém no mesmo nível do caso anterior, mas o modelo conseguiu fazer um melhor aproveitamento dos motoristas com a ampliação do período programado.

Em ambos os casos foi possível reduzir o número de motoristas e o total de horas extras pagas pelas empresas, zerando a ociosidade existente nas soluções produzidas manualmente. A redução dos custos variáveis é significativa, de aproximadamente $13 \%$ da remuneração da mão de obra operacional, item de maior peso nos custos das empresas de transporte público.

\section{Conclusões}

Neste trabalho, o PRT é resolvido em duas etapas: um primeiro modelo de designação foi aplicado iterativamente para gerar uma sequência de jornadas diárias para cada tripulação, com o menor número possível de horas extras atribuídas no período de planejamento. Neste modelo foram consideradas restrições peculiares à legislação brasileira e à prática adotada pelas empresas estudadas. Como o modelo de designação não prevê as folgas legais, este trabalho apresentou ainda um modelo de programação linear inteira, ainda inédito na literatura, que resolve o problema de alocação dos folguistas no sistema de transporte público brasileiro. 
O modelo de designação foi empregado para solucionar uma série de subproblemas de menor complexidade e obter soluções parciais que, combinadas, geraram uma solução parcialmente ótima. O modelo de programação inteira encontra e aloca o número mínimo necessário de folguistas para que todas as tripulações tenham suas folgas legais atendidas. Porém, o rodízio pode ser reotimizado considerando agora o total de motoristas disponíveis, ou seja, os "titulares" mais os folguistas. Desta maneira é possível que o número de horas extras seja reduzido ainda mais. Apesar desta reotimização não ter sido implementada, as soluções obtidas neste trabalho se mostraram competitivas com consideráveis melhorias em relação às soluções fornecidas pelas empresas. No caso da Empresa A, mesmo eliminando uma série de motoristas da escala, a solução otimizada se mostrou superior permitindo reduções significativas no número de motoristas e nas horas extras.

Os testes comparativos foram realizados com dados reais de duas empresas brasileiras, sendo que a primeira forneceu a escala realizada no período e a segunda forneceu a escala planejada para o período. Foram detectadas incongruências nos dados da primeira empresa o que dificultou a sua comparação com a solução otimizada. De acordo com a empresa, os dados foram capturados pelo sistema de ponto eletrônico o que confere sua credibilidade. Entretanto, ao compilar estes dados foi observado que quase a metade dos motoristas trabalhou menos do que dez dias de um total de trinta e cinco dias do período estudado. Por outro lado, cerca de $10 \%$ do total de motoristas trabalharam com ociosidade média acima de duas horas por dia. Assim pode ser concluído que: i) a empresa é muito ineficiente na gestão mensal de seus motoristas, e/ou ii) os dados não se referem apenas ao sistema de ônibus urbano, e os motoristas atuam simultaneamente em outras atividades não incluídas no modelo (linhas intermunicipais), e/ou iii) o sistema de informação não capturou os dados de maneira precisa.

Os dados e a solução da segunda empresa partem de uma mesmo hipótese, que diz respeito à programação da escala ainda não realizada. Também neste caso os resultados obtidos pelo método são melhores do que as soluções propostas pela empresa com a redução de $8,46 \%$ no número de tripulações e de 13,00\% na quantidade de horas extras. As reduções alcançadas estão de acordo com resultados obtidos em trabalhos anteriores e dentro da normalidade quando se trata da substituição de soluções manuais por soluções otimizadas no sistema de transporte público. 
O modelo proposto ainda se encontra em sua primeira versão, portanto apresenta possibilidades de aprimoramento, especialmente no que se refere à flexibilização do horizonte de planejamento e ao tratamento das tripulações do tipo folguista. Um possível melhoramento consiste em reprogramar a solução final considerando fixo o total de tripulações e minimizando o total de horas extras contidas no rodízio.

Finalmente, pode-se concluir que um estudo mais preciso de um caso real do PRT é extremamente difícil, pois ao longo de um período de cinco semanas pode haver diversas ocorrências inevitáveis e intangíveis que comprometem a apuração dos dados e dificultam uma comparação precisa da solução otimizada com a solução da empresa.

\section{Referências}

Baker, K. (1974) Scheduling a full-time workforce to meet cyclic staffing requirements. Management Sciences. vol. 20, pp. 1561-1568.

Bianco, L., Bielli, M., Mingozzi, A., Ricciardelli, S. e Spadoni, M. (1992) A heuristic procedure for the crew rostering problem. European Journal of Operations Research, vol. 58, n. 2, pp. 272283.

Ahuja, R. K., Magnanti, T.L. e Orlin, J.B. (1993). Network Flows: Theory, Algorithms, and Applications. Prentice Hall, N. J.

Bodin, L., Golden, B.; Assad, A. e Ball, M. (1983) Routing and scheduling of vehicles and crews: The state of the art. Computers and Operations Research, vol. 10, pp. 63-211.

Carraresi, P. e Gallo, G. (1984) A multi-level bottleneck assignment approach to the bus drivers' rostering problem. European Journal of Operations Research, vol. 16, pp. 163-173.

Daduna, J. R. e Paixão, J. M. P. (1995) Vehicle scheduling for public mass transport- an overview. In: Daduna, J. R., I. Branco e J. M. P. Paixão (eds.) Computer-Aided Transit Scheduling, Lectures Notes in Economics and Mathematical Systems. Springer Verlag, Berlin, Alemanha.

Ernst, A. T., Jiang, H., Krishnamoorthy, M., Owens, B. e Sier, D. (2004a) Staff scheduling and rostering: A review of applications, methods and models. European Journal of Operational Research, vol. 153, pp. 3-27.

Ernst, A. T., Jiang, H., Krishnamoorthy, M., Owens, B. e Sier, D. (2004b) An annotated bibliography of personnel scheduling and rostering. Annals of Operations Research, vol. 127, pp. 21-144.

Silva, G. P. (2001) Uma metodologia baseada na técnica de geração de arcos para o problema de programação de veículos. Tese (Doutorado em Engenharia de Transportes), Universidade de São Paulo, São Paulo.

Silva, G. P., Coelho, B., N. e Souza, M. J. F. (2007a) Integração Horizontal na Operação dos Veículos de uma Região Metropolitana. Anais do Congresso latino americano de Transporte Público y Urbano, Rio de Janeiro. 
Silva, G. P., Souza, M. J. F. e Reis, J. von A. (2007b) Análise Comparativa de Métodos para Resolver o Problema de Programação de Tripulações. Revista Produção OnLine, vol. 07, n. 02, pp. 126143.

Souza, M. J. F., Silva, G. P. e Simões, E. L. (2006) Programação de Ônibus Urbano: Uma Abordagem Heurística. Panorama Nacional da Pesquisa e Ensino em Transportes 2006. Associação Nacional de Pesquisa e Ensino em Transportes, vol. 2. pp. 705-716, Rio de Janeiro, Brasil.

Yunes, T. (2000) Problemas de Escalonamento no Transporte Coletivo: Programação por Restrição e Outras Técnicas. Dissertação (Mestrado em Ciência da Computação), Unicamp, Campinas. 